Cite this: Chem. Sci., 2014, 5, 501

\title{
Ruthenium-catalysed Z-selective cross metathesis of allylic-substituted olefins $\dagger$
}

\author{
Brendan L. Quigley and Robert H. Grubbs* \\ The Z-selective cross metathesis of allylic-substituted olefins is explored with recently developed \\ ruthenium-based metathesis catalysts. The reaction proceeds with excellent stereoselectivity for the $Z$ - \\ isomer (typically $>95 \%$ ) and yields of up to $88 \%$ for a variety of allylic substituents. This includes the first \\ synthesis of $Z-\alpha, \beta$-unsaturated acetals by cross metathesis and their elaboration to $Z$ - $\alpha, \beta$-unsaturated \\ aldehydes. In addition, the reaction is tolerant of a variety of cross partners, varying in functionality and \\ steric profile.
}

Received 9th October 2013

Accepted 29th October 2013

DOI: $10.1039 / c 3 s c 52806 e$

www.rsc.org/chemicalscience

\section{Introduction}

Transition metal-catalysed olefin metathesis is a powerful tool for the synthesis of carbon-carbon double bonds in a wide variety of applications. ${ }^{1}$ However, a major limitation of metathesis has been the lack of a method to selectively generate the $Z$-olefin product. ${ }^{2}$ The recent advent of metathesis catalysts that have a preference for the $Z$-isomer has, for the first time, allowed $Z$-alkenes to be produced in a general manner. ${ }^{3,4}$ Though high $Z$-selectivity has been achieved, the broad reactivity profile characteristic of previous generations of metathesis catalysts is still under development.

Ruthenium-based catalysts that contain a chelating NHC ligand, such as 1 and 2 (Fig. 1), are one class of the recently developed $Z$-selective metathesis catalysts. ${ }^{4,5}$ In these catalysts, the chelating $N$-adamantyl substituent ${ }^{6}$ and bidentate nitrato ligand ${ }^{7}$ were found to be key to achieving high $Z$-selectivity across a broad range of reactions, including ethenolysis, ${ }^{8}$ macrocyclic ring-closing metathesis, ${ }^{9}$ ring-opening metathesis polymerization, ${ }^{10}$ asymmetric ring-opening cross metathesis, ${ }^{11}$ as well as in the more broadly applicable cross metathesis (CM) of two terminal olefins., ${ }^{4,5,12,13}$ In particular, catalyst 2 has demonstrated $Z$-selectivities of $>95 \%$ while achieving turnover numbers of $\sim 7000$ in cross metathesis of unhindered terminal olefins. ${ }^{5}$ In contrast, allylic-substituted olefins represent a more challenging class of substrates for $Z$-selective cross metathesis. Allylic substitution introduces increased steric bulk, which can further destabilize the cis-conformation over the trans-conformation of the carbon-carbon double bond. ${ }^{14}$ Notably, this results in highly selective formation of the $E$-product (often $>90 \%$ ) with previous generations of $\mathrm{Ru}$ metathesis catalysts

Arnold and Mabel Beckman Laboratories of Chemical Synthesis, Division of Chemistry and Chemical Engineering, California Institute of Technology, Pasadena, California 91125, USA. E-mail: rhg@caltech.edu

$\uparrow$ Electronic supplementary information (ESI) available: Experimental procedures and spectroscopic data for all new compounds. See DOI: 10.1039/c3sc52806e such as 3 and $4 .^{15,16}$ While cross metathesis of some allylicsubstituted olefins has been very recently achieved with $Z$-selective Mo-based catalysts (e.g. 5 and 6), ${ }^{17,18}$ this has not been explored with $Z$-selective Ru-based catalysts. Previous results have demonstrated that substrates with allylic substitution undergo negligible conversion in homodimerization reactions due to the high strain of the products; ${ }^{4,13}$ however, their reactivity in hetero-cross metathesis has not been explored. ${ }^{19} \mathrm{Ru}$-based metathesis catalysts in general show broad functional group tolerance and are comparatively air and water stable, lending them to many applications. ${ }^{16,20}$ Achieving cross metathesis of allylic-substituted olefins represents an important and essential advance in expanding the reactivity profile of $Z$-selective Ru-based metathesis catalysts.

Vinyl acetals were identified as important allylic-substituted olefins which had not been explored in $Z$-selective metathesis with either $\mathrm{Ru}$ - or $\mathrm{Mo} / \mathrm{W}$-based catalysts. The products afforded, namely $Z$ - $\alpha, \beta$-unsaturated acetals, also serve as precursors to the corresponding $Z$ - $\alpha, \beta$-unsaturated aldehydes. $E$ - $\alpha, \beta$-Unsaturated aldehydes are available utilizing earlier generations of
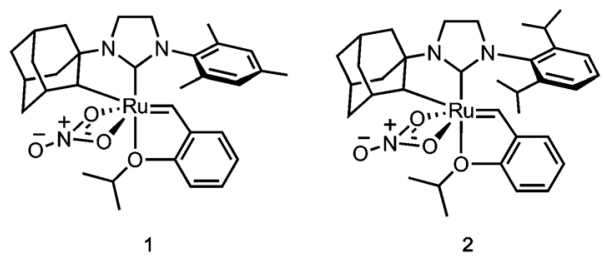<smiles>PC=[Te](Cl)(Cl)Cl</smiles>
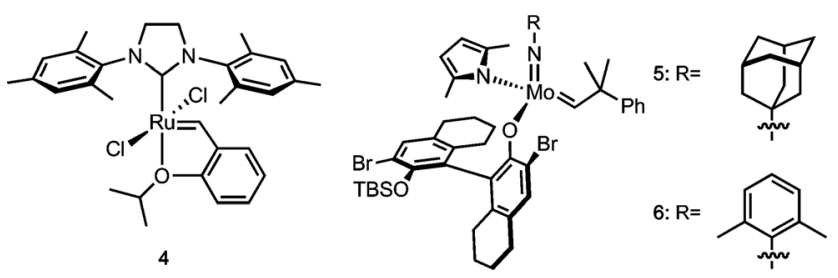

Fig. 1 Ruthenium- and molybdenum-based metathesis catalysts. 
metathesis catalysts. ${ }^{15}$ Both classes of compounds are of significant interest for a variety of applications. A number of naturally occurring $Z$ - $\alpha, \beta$-unsaturated aldehydes contribute to the scents of various plants and are therefore of interest to the fragrance industry. ${ }^{21}$ These functionalities also occur in pheromones of several insect species and are potentially of use for mating-disruption as an environmentally friendly alternative to pesticides. $^{22}$ In both plants and animals, $Z$ - $\alpha, \beta$-unsaturated aldehydes are produced during metabolism and their relative abundance is regulated by a number of external and internal stimuli. As a result, some cancer detection and food quality assays rely on these compounds as key indicators. ${ }^{23} Z$ - $\alpha, \beta$ Unsaturated acetals and aldehydes also have significant synthetic utility, resulting in their appearance as key intermediates in the synthesis of a number of natural products. ${ }^{24}$ Furthermore, $\alpha, \beta$-unsaturated acetals have been extensively explored as substrates for a number of base- and metalpromoted rearrangements. ${ }^{25}$ However, while $Z$ - $\alpha, \beta$-unsaturated acetals and aldehydes are much sought after, general, broad methods for their synthesis are rare.

Reagents have been developed for the two-carbon homologation of aldehydes to the corresponding $\alpha, \beta$-unsaturated compounds, but achieving high $Z$-stereoselectivity is often challenging and unpredictable. ${ }^{26}$ This results in the employment of less efficient, multi-step methods. ${ }^{27}$ For example, the Still-Gennari modification of the Horner-Wadsworth-Emmons reaction $^{28}$ affords the $Z$ - $\alpha, \beta$-unsaturated ester, which can then be reduced to the allylic alcohol and oxidized to afford the aldehyde. In an alternative strategy, alkynyl acetals can be generated by cross-coupling or alkylation, subsequent semihydrogenation (typically with Lindlar's catalyst) and deprotection to yield the desired product. $Z$-Selective metathesis represents an attractive route to $\alpha, \beta$-unsaturated acetals and aldehydes that overcomes several shortcomings of the abovementioned methods. Previous methods necessitate the use of strong bases, sensitive organometallic complexes or redox reagents resulting in extensive functional group protections of complex molecules. ${ }^{\mathbf{2 4 2 6 - 2 8}}$ In contrast, $Z$-selective metathesis is a more direct method with broad functional group tolerance, reducing the need for protecting groups. In addition, both starting materials are readily available/accessible: vinyl acetals can be efficiently prepared from acrolein ${ }^{29}$ and cross partners can be sourced from the vast olefin chemical feedstock.

\section{Results and discussion}

We selected vinyl acetal 7 to explore the optimization of the reaction conditions (Table 1 ). Acetal 7 is commercially available and the 1,3-dioxolane derivative has enhanced stability to silica gel over acyclic acetals, making it one of the most commonly employed carbonyl protecting groups. ${ }^{30}$ 1-Dodecene (8) was chosen as a cross partner due to its low volatility and known homodimerization by 1 and 2.,13 Initial conditions utilised 6 equivalents of $\mathbf{8}$ and $5 \mathrm{~mol} \%$ of catalyst $\mathbf{2}$ (entry 1). Under these conditions, product 9 was generated in good yield and high $Z$ selectivity, with maximum conversion reached at 3 hours. A reduction in the equivalents of $\mathbf{8}$ and a decrease in catalyst
Table 1 Optimization of CM reaction between vinyl dioxolane (7) and 1-dodecene (8)

\begin{tabular}{|c|c|c|c|c|c|}
\hline & + & eq. $\underset{ }{ }{ }_{8}$ & $\begin{array}{l}\mathbf{2}(1 \\
\text { THF } \\
35^{\circ}\end{array}$ & & 9 \\
\hline Entry & $\begin{array}{l}2 \\
(\mathrm{~mol} \%)\end{array}$ & $\begin{array}{l}7 \\
\text { Equiv. }\end{array}$ & $\begin{array}{l}\text { Conc. } \\
\text { (M) }\end{array}$ & $\begin{array}{l}\text { Yield }^{a} \\
(\%)\end{array}$ & $\begin{array}{l}Z \text {-Selectivity }{ }^{a} \\
(\%)\end{array}$ \\
\hline 1 & 5 & 6 & 0.5 & 84 & 93 \\
\hline 2 & 5 & 4 & 0.5 & 87 & 94 \\
\hline 3 & 5 & 2 & 0.5 & 80 & 95 \\
\hline 4 & 2 & 4 & 0.5 & 83 & 95 \\
\hline 5 & 2 & 4 & 0.3 & 92 & 94 \\
\hline 6 & 2 & 2 & 0.5 & 80 & 95 \\
\hline 7 & 2 & 2 & 1.0 & 66 & 95 \\
\hline 8 & 2 & 2 & 0.3 & $82[87]^{b}$ & $95[94]^{b}$ \\
\hline 9 & 1 & 2 & 0.5 & 74 & 95 \\
\hline
\end{tabular}

${ }^{a}$ Yield and $Z$-selectivity determined by GC using tridecane as an internal standard; average of two experiments. ${ }^{b}$ Value at 7 hours.

loading were then examined (entries 2-4). Four equivalents of terminal olefin and $2 \mathrm{~mol} \%$ of catalyst were found to be optimal, giving a similar yield and slightly improved $Z$-selectivity to initial conditions. Lowering the concentration (entry 5) led to a significant increase in yield, generating product 9 in $92 \%$ yield and with $94 \% Z$-selectivity. It is worth noting that across the variety of reaction conditions explored, the $Z$-selectivity remained consistently high. Further reductions in the excess of terminal olefin and lowering of catalyst loading were both viable but led to longer reaction times and a slight reduction in yield (entries 6-9). In order to demonstrate the versatility of this method, we also explored conditions in which 8 was used as the limiting reagent (Table 2, entries 1-2). Although longer reaction times were required, using 4 equivalents of 7 was found to give comparable yield of product with high $Z$-selectivity. As in the case of excess 8 (entries 3-4), using 2 equivalents resulted in a lower yield.

Under the optimized conditions, we explored reactivity of a number of commercially available Ru-based metathesis catalysts including $Z$-selective catalyst $\mathbf{1}$, as well as the commonly

Table 2 CM of vinyl dioxolane (7) and 1-dodecene (8), varying the ratio of 7 to 8

\begin{tabular}{|c|c|c|c|c|}
\hline & 7 & $=x x_{9}$ & $\begin{array}{l}\frac{2(2 \mathrm{~mol} \%)}{\operatorname{THF}(0.3 \mathrm{M})} \\
35^{\circ} \mathrm{C}, 3 \mathrm{~h} .\end{array}$ & $\int_{9} \lambda_{9}^{1+}$ \\
\hline Entry & 7 Equiv. & 8 Equiv. & Yield $^{a}(\%)$ & $Z$-Selectivity ${ }^{a}(\%)$ \\
\hline 1 & 2 & 1 & $63[84]^{b}$ & $93[92]^{b}$ \\
\hline 2 & 4 & 1 & $65[94]^{b}$ & $91[91]^{b}$ \\
\hline 3 & 1 & 2 & 82 & 95 \\
\hline 4 & 1 & 4 & 92 & 94 \\
\hline
\end{tabular}

${ }^{a}$ Yield and $Z$-selectivity determined by GC using tridecane as an internal standard; average of two experiments. ${ }^{b}$ Value at 7 hours. 
employed bis-phosphine catalyst 3 and NHC-substituted catalyst 4. Notably, catalyst 2 generated product 9 in $94 \% Z$-selectivity (Table 3, entry 2). This is in strong contrast to catalyst $\mathbf{1}$, the previously best $Z$-selective Ru catalyst, which only achieved $76 \%$ selectivity for the $Z$-isomer (entry 1 ), clearly highlighting the improved selectivity of catalyst 2 over 1 . Both $Z$-selective catalysts complement previous generations of Ru-complexes ( 3 and 4), which yield the more thermodynamically stable $E$-olefin as the major product in comparable yield (entries 3 and 4). It is worth noting that both isomers of product $\mathbf{9}$ can be generated in high yield and selectivity with Ru-based metathesis catalysts.

The reaction substrate scope was investigated on a preparative scale $(0.8-1.0 \mathrm{mmol})$ with catalyst 2 and we were pleased to find these conditions were applicable to a variety of vinyl acetals (Table 4). ${ }^{31}$ Vinyl dioxolane cross product (9) was afforded in $82 \%$ isolated yield and with $>95 \% Z$-selectivity. Other five and six-membered acetal substrates (10-12) performed consistently well, yielding the desired product in $79-85 \%$ yield and $>95 \% Z$-selectivity. In the case of dimeric acetal 13, the $Z, Z$-product is afforded as the major isomer $(89 \%)$ and the $Z, E$-isomer is the only other observed product $(11 \%)$. This is consistent with the statistical outcome of two independent steps of $\sim 94 \% Z$-selectivity. ${ }^{32}$ The acyclic diethyl acetal afforded cross product $\mathbf{1 4}$ in high $Z$-selectivity, albeit at a slightly reduced yield. Attempts to extend this methodology to related olefins with quaternary allylic substitution (vinyl ketals and orthoesters) have so far been met with limited success.

In order to provide further insight into reactivity, we decided to probe a variety of other substrates with related allylic functionalities. Vinyl pinacol boronate has previously been shown to afford highly trans cross products with catalyst 3 (typically, $>95 \% E){ }^{15,33}$ Such products are of use for subsequent Suzuki cross-coupling reactions, where olefin geometry can be efficiently transferred. ${ }^{34}$ Here, $Z$-cross product 15 could be generated in good yield (81\%) and high $Z$-selectivity $(92 \%)$. This result compares favourably with a report by Schrock, Hoveyda and coworkers, except here the typically less expensive terminal olefin can be used in excess. ${ }^{17}$ Additionally, we investigated 2-vinyloxirane as a substrate for this reaction. Though cross product 16

Table 3 CM of vinyl dioxolane (7) and 1-dodecene (8) using various Ru-metathesis catalysts

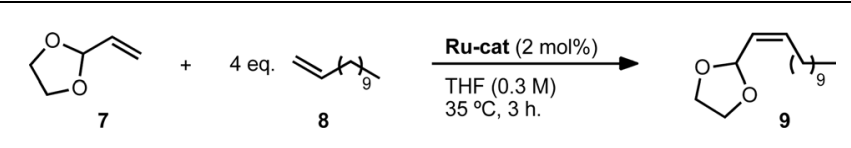

\begin{tabular}{llll}
\hline Entry & Catalyst & Yield $^{a}(\%)$ & $Z$ Selectivity $^{a}(\%)$ \\
\hline 1 & $\mathbf{1}$ & 87 & 76 \\
2 & $\mathbf{2}$ & 92 & 94 \\
3 & $\mathbf{3}$ & 96 & 10 \\
4 & $\mathbf{4}$ & 92 & 5
\end{tabular}

${ }^{a}$ Yield and $Z$-selectivity determined by GC using tridecane as an internal standard; average of two experiments.
Table 4 CM of allylic-substituted olefins with 1-dodecene $(8)^{a}$

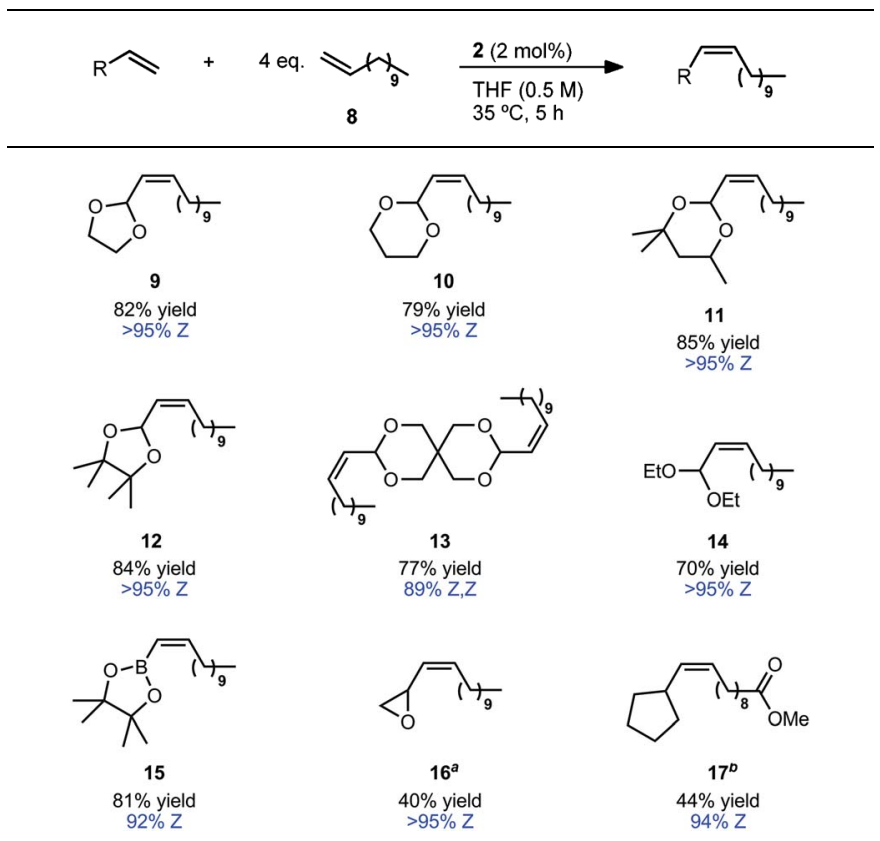

${ }^{a}$ Isolated yields. Z-Selectivity determined by ${ }^{1} \mathrm{H}$ NMR (see ESI for details). ${ }^{b}$ Reaction conducted at $20{ }^{\circ} \mathrm{C}$. ${ }^{c}$ Methyl-10-undecenoate was used in place of $\mathbf{8}$.

could be formed in excellent $Z$-selectivity, the reaction proceeded in only moderate yield..$^{35}$

The reactivity of vinyl cyclopentane, the all-carbon analogue of substrate 7 , was then examined. In this case, methyl-10-undecenoate was used in order to facilitate separation of the cross product from the homodimer of the terminal olefin. While $Z$-selectivity of product $\mathbf{1 7}$ was good (94\%), the yield was significantly lower than that for $9(44 \% v s$. $82 \%)$. Increased catalyst loading or gradual addition of vinyl cyclopentane were unsuccessful in restoring the high yields observed in the case of the acetal. Furthermore, vinyl cyclohexane, which is more sterically demanding, demonstrated vastly diminished reactivity, with only minimal conversion after 5 hours.

An important factor in achieving a synthetically useful $Z$ selective CM methodology is tolerance of functional groups that are present in complex molecules. Reaction conditions were found to be compatible with a variety of terminal olefins, which formed cross products with 7 in $72-88 \%$ yield and $89->95 \% \mathrm{Z}$ selectivity (Table 5). Notably, several moieties useful for further functionalization could be incorporated, including unprotected alcohols (20) ${ }^{36}$ and alkyl bromides (21). Though cross metathesis with $N$-allylaniline resulted in a reduced yield $(18 \%$ yield, $94 \% Z$ ), reactivity was restored on protection with a benzyl group. The increased steric bulk, however, likely resulted in the slightly reduced $Z$-selectivity noted for product 22 ( $72 \%$ yield, $89 \% Z$ ). Allyl pinacol boronate, a moiety useful for subsequent stereospecific allylation, ${ }^{17,37}$ was also found to be compatible with the reaction conditions generating product 23 in $>95 \% Z$ - 
Table 5 CM of vinyl dioxolane (7) with various terminal olefins ${ }^{a}$

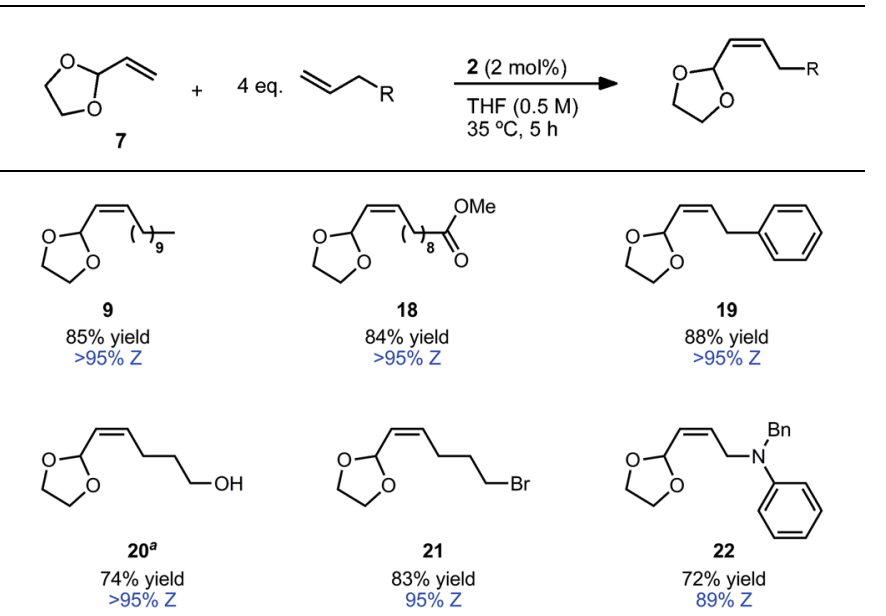

${ }^{a}$ Isolated yields. Z-Selectivity determined by ${ }^{1} \mathrm{H}$ NMR (see ESI for details). ${ }^{b}$ Reaction stopped at 3 hours.

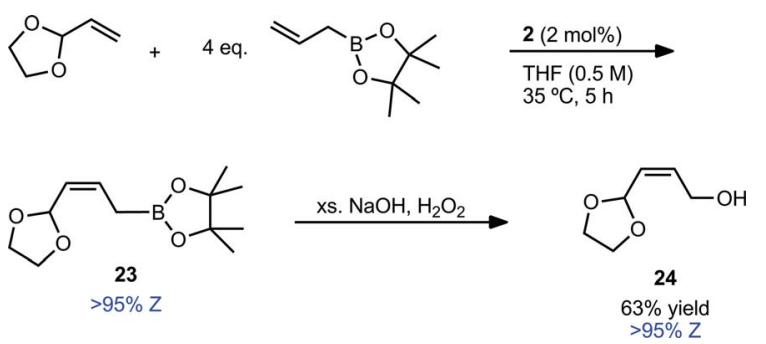

Scheme 1 CM of vinyl dioxolane (7) and allyl pinacol boronate and one-pot conversion to allylic alcohol.

selectivity (Scheme 1). In order to facilitate purification, 23 was converted to $Z$-allylic alcohol $\mathbf{2 4}$, which was obtained in good yield and high $Z$-selectivity over the two steps $(63 \%$ yield, $>95 \% Z$ ).

One of the most important uses of $Z$ - $\alpha, \beta$-unsaturated acetals is as precursors to the corresponding $Z$ - $\alpha, \beta$-unsaturated aldehydes. However, achieving stereo-retentive deprotection is nontrivial and there are only a handful of previous examples in the literature..$^{27 b, 38}$ Therefore, a number of conditions were evaluated for deprotection of acetals without loss of $Z$-stereoselectivity (Table 6). Alkenyl acetals $\mathbf{9}$ and $\mathbf{1 1}$ were selected as they contain two of the most commonly utilised acetal functionalities. ${ }^{30}$ Deprotection could be effected with Brønsted acid for both 9 and 11 using previously reported reagents (entries 1 and 2). ${ }^{39}$ Additionally, $\mathrm{LiBF}_{4}{ }^{40}$ which had not been previously utilised for deprotection of $Z$ - $\alpha, \beta$-unsaturated acetals, could also effect the deprotection with excellent retention of alkene stereochemistry (entries 3 and 4 ). ${ }^{41}$ This mild method of cleaving the acetal has been demonstrated to be compatible with a wide variety of functional groups. ${ }^{40,42}$ This would allow incorporation of the more-stable $Z$ - $\alpha, \beta$-unsaturated acetal as a
Table 6 Deprotection of alkenyl dioxolane 9 and alkenyl diethyl acetal 11

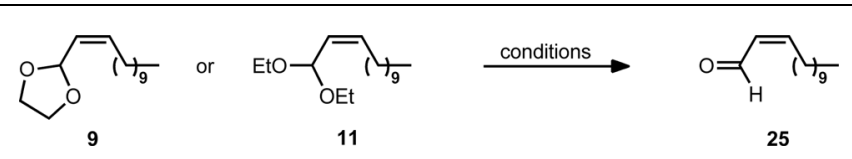

\begin{tabular}{|c|c|c|c|c|c|}
\hline \multirow[b]{2}{*}{ Entry } & \multirow[b]{2}{*}{ Subst. } & \multirow[b]{2}{*}{ Reagents } & \multicolumn{2}{|c|}{$Z$-Selectivity (\%) } & \multirow[b]{2}{*}{ Yield (\% } \\
\hline & & & Initial & Final & \\
\hline 1 & 9 & $\mathrm{SiO}_{2}$, oxalic acid ${ }^{a}$ & $>95$ & $>95$ & Quant. \\
\hline 2 & 11 & $\mathrm{SiO}_{2}$, oxalic acid ${ }^{a}$ & $>95$ & $>95$ & Quant. \\
\hline 3 & 9 & $\mathrm{LiBF}_{4}{ }^{b}$ & $>95$ & $>95$ & 95 \\
\hline 4 & 11 & $\mathrm{LiBF}_{4}{ }^{b}$ & $>95$ & $>95$ & 92 \\
\hline
\end{tabular}

${ }^{a} \mathrm{SiO}_{2} 2.5 \mathrm{~g} \mathrm{mmol}^{-1}$ with 9/11; $5 \%$ aq. oxalic acid $10 \% \mathrm{w} / \mathrm{w}$ with $\mathrm{SiO}_{2}$; DCM (0.05 M); r.t., 10 min. ${ }^{b} 1.3$ eq. $\mathrm{LiBF}_{4} ; 97: 3 \mathrm{MeCN}: \mathrm{H}_{2} \mathrm{O}(0.1 \mathrm{M})$; r.t. $10 \mathrm{~min}$.

masked aldehyde that can be deprotected when needed, lending this methodology to the synthesis of complex molecules.

\section{Conclusions}

In summary, we have demonstrated that a single rutheniumbased metathesis catalyst can effect the $Z$-selective cross metathesis of a variety of allylic-substituted olefins with stereoselectivity for the $Z$-olefin typically in excess of $95 \%$. In doing so, we have developed a mild method for the synthesis of $Z-\alpha, \beta-$ unsaturated acetals and aldehydes that delivers excellent stereoselectivity and is compatible with a variety of functional groups. Further exploration of reactivity with sterically hindered olefins in tandem with continued development of new catalysts offers the potential to afford $Z$-olefins with the broad reactivity profile exhibited by previous generations of ruthenium metathesis catalysts.

\section{Acknowledgements}

This work was financially supported by the NIH (R01GM031332). NMR spectra were obtained on instruments funded by the NIH (RR027690). Materia Inc. is gratefully acknowledged for donation of metathesis catalysts 1-4. S. M. Bronner, J. S. Cannon, M. B. Herbert and V. M. Marx are thanked for helpful discussion.

\section{Notes and references}

1 (a) G. C. Vougioukalakis and R. H. Grubbs, Chem. Rev., 2009, 110, 1746-1787; (b) R. R. Schrock, Chem. Rev., 2009, 109, 3211-3226; (c) J. C. Mol, J. Mol. Catal. A: Chem., 2004, 213, 39-45; (d) J. B. Binder and R. T. Raines, Curr. Opin. Chem. Biol., 2008, 12, 767-773; (e) M. S. Trimmer, in Handbook of Metathesis, Wiley-VCH Verlag $\mathrm{GmbH}$, Weinheim, Germany, 2008, vol. 3, pp. 407-418; (f) J. Prunet, Curr. Top. Med. Chem., 2005, 5, 1559-1577. 
2 D. Lee, Nature, 2011, 471, 452-453.

3 (a) M. M. Flook, A. J. Jiang, R. R. Schrock and A. H. Hoveyda, J. Am. Chem. Soc., 2009, 131, 7962-7963; (b) I. Ibrahem, M. Yu, R. R. Schrock and A. H. Hoveyda, J. Am. Chem. Soc., 2009, 131, 3844-3845; (c) R. K. M. Khan, S. Torker and A. H. Hoveyda, J. Am. Chem. Soc., 2013, 135, 10258-10261; (d) G. Occhipinti, F. R. Hansen, K. W. Törnroos and V. R. Jensen, J. Am. Chem. Soc., 2013, 135, 3331-3334.

4 (a) K. Endo and R. H. Grubbs, J. Am. Chem. Soc., 2011, 133, 8525-8527; (b) B. K. Keitz, K. Endo, P. R. Patel, M. B. Herbert and R. H. Grubbs, J. Am. Chem. Soc., 2012, 134, 693-699.

5 L. E. Rosebrugh, M. B. Herbert, V. M. Marx, B. K. Keitz and R. H. Grubbs, J. Am. Chem. Soc., 2013, 135, 12761279.

6 For examples of previous non-chelated Ru-based metathesis catalysts with $N$-adamantyl NHCs see: $(a)$ M. B. Dinger, P. Nieczypor and J. C. Mol, Organometallics, 2003, 22, 52915296; (b) M. Mayr, B. Mayr and M. R. Buchmeiser, Angew. Chem., Int. Ed., 2001, 40, 3839-3842; (c) M. R. Buchmeiser, Biorg. Med. Chem. Lett., 2002, 12, 1837-1840.

7 Previously nitrato ligands have been shown to decrease activity for other Ru-based metathesis catalysts: (a) M. Jović, S. Torker and P. Chen, Organometallics, 2011, 30, 3971-3980; (b) M. R. Buchmeiser, I. Ahmad, V. Gurram and P. S. Kumar, Macromolecules, 2011, 44, 4098-4106.

8 H. Miyazaki, M. B. Herbert, P. Liu, X. Dong, X. Xu, B. K. Keitz, T. Ung, G. Mkrtumyan, K. N. Houk and R. H. Grubbs, J. Am. Chem. Soc., 2013, 135, 5848-5858.

9 V. M. Marx, M. B. Herbert, B. K. Keitz and R. H. Grubbs, J. Am. Chem. Soc., 2013, 135, 94-97.

10 (a) B. K. Keitz, A. Fedorov and R. H. Grubbs, J. Am. Chem. Soc., 2012, 134, 2040-2043; (b) L. E. Rosebrugh, V. M. Marx, B. K. Keitz and R. H. Grubbs, J. Am. Chem. Soc., 2013, 135, 10032-10035.

11 J. Hartung and R. H. Grubbs, J. Am. Chem. Soc., 2013, 135, 10183-10185.

12 (a) M. B. Herbert, V. M. Marx, R. L. Pederson and R. H. Grubbs, Angew. Chem., Int. Ed., 2013, 52, 310-314; (b) J. S. Cannon and R. H. Grubbs, Angew. Chem., Int. Ed., 2013, 52, 9001-9004.

13 B. K. Keitz, K. Endo, M. B. Herbert and R. H. Grubbs, J. Am. Chem. Soc., 2011, 133, 9686-9688.

14 R. B. Turner, A. D. Jarrett, P. Goebel and B. J. Mallon, J. Am. Chem. Soc., 1973, 95, 790-792.

15 H. E. Blackwell, D. J. O'Leary, A. K. Chatterjee, R. A. Washenfelder, D. A. Bussmann and R. H. Grubbs, J. Am. Chem. Soc., 2000, 122, 58-71.

16 A. K. Chatterjee, T.-L. Choi, D. P. Sanders and R. H. Grubbs, J. Am. Chem. Soc., 2003, 125, 11360-11370.

17 E. T. Kiesewetter, R. V. O’Brien, E. C. Yu, S. J. Meek, R. R. Schrock and A. H. Hoveyda, J. Am. Chem. Soc., 2013, 135, 6026-6029.

18 T. J. Mann, A. W. Speed, R. R. Schrock and A. H. Hoveyda, Angew. Chem., Int. Ed., 2013, 52, 8395-8400.

19 While this manuscript was in preparation, a single catalytic example was reported: W.-J. Chung, J. S. Carlson, D. K. Bedke and C. D. Vanderwal, Angew. Chem., Int. Ed., 2013, 52, 1005210055.

20 (a) S. J. Connon and S. Blechert, Angew. Chem., Int. Ed., 2003, 42, 1900-1923; (b) T. M. Trnka and R. H. Grubbs, Acc. Chem. Res., 2000, 34, 18-29.

21 (a) M. H. Boelens and L. J. van Gemert, Perfum. Flavor., 1987, 12, 31-43; (b) G. Ohloff, W. Pickenhagen and P. Kraft, Scent and Chemistry, Wiley-VCH Verlag GmbH, Weinheim, Germany, 2012.

22 (a) E. B. Jang, M. S. Siderhurst, R. G. Hollingsworth, D. N. Showalter and E. J. Troyer, Pest Manage. Sci., 2010, 66, 454-460; (b) P. E. Howse, I. D. R. Stevens and O. T. Jones, Insect Pheromones and their Use in Pest Management, Chapman and Hall, New York, 1998.

23 (a) K. Jobu, C. Sun, S. Yoshioka, J. Yokota, M. Onogawa, C. Kawada, K. Inoue, T. Shuin, T. Sendo and M. Miyamura, Biol. Pharm. Bull., 2012, 35, 639-642; (b) F. M. Haddada, H. Manai, D. Daoud, X. Fernandez, L. Lizzani-Cuvelier and M. Zarrouk, Food Chem., 2007, 103, 467-476; (c) S. D. Johanningsmeier and R. F. McFeeters, J. Food Sci., 2011, 76, C168-C177; (d) B. T. Kebede, T. Grauwet, G. Tabilo-Munizaga, S. Palmers, L. Vervoort, M. Hendrickx and A. Van Loey, Food Chem., 2013, 141, 1603-1613; (e) T. Balboa-Lagunero, T. Arroyo, J. M. Cabellos and M. Aznar, Am. J. Enol. Vitic., 2011, 52, 527-535.

24 (a) T. Brodmann, D. Janssen and M. Kalesse, J. Am. Chem. Soc., 2010, 132, 13610-13611; (b) W. Roush, D. Coffey and D. Madar, J. Am. Chem. Soc., 1997, 119, 11331-11332; (c) I. Paterson, G. J. Florence, K. Gerlach and J. P. Scott, Angew. Chem., Int. Ed., 2000, 39, 377-380; (d) H. J. Bestmann, O. Vostrowsky, H. Paulus, W. Billmann and W. Stransky, Tetrahedron Lett., 1977, 18, 121-124; (e) A. I. Gerasyuto and R. P. Hsung, J. Org. Chem., 2007, 72, 2476-2484.

25 A. Deagostino, C. Prandi and P. Venturello, Curr. Org. Chem., 2003, 7, 821-839.

26 (a) T. Cresp, M. Sargent and P. Vogel, J. Chem. Soc., Perkin Trans. 1, 1974, 37-41; (b) N. Daubresse, C. Francesch and C. Rolando, Tetrahedron, 1998, 54, 10761-10770; (c) J. Nuzillard, A. Boumendjel and G. Massiot, Tetrahedron Lett., 1989, 30, 3779-3780; (d) R. J. Petroski, K. Vermillion and A. A. Cossé, Molecules, 2011, 16, 5062-5078; (e) G. Wittig and H. Reiff, Angew. Chem., Int. Ed., 1968, 7, 7-14; (f) R. H. Wollenberg, K. F. Albizati and R. Peries, J. Am. Chem. Soc., 1977, 99, 348-352.

27 (a) S. J. Shaw, K. F. Sundermann, M. A. Burlingame, D. Zhang, J. Petryka and D. C. Myles, Biorg. Med. Chem. Lett., 2006, 16, 1961-1964; (b) S. Zhou, T. Xiao, H. Song and X. Zhou, Tetrahedron Lett., 2012, 53, 5684-5687.

28 W. Still and C. Gennari, Tetrahedron Lett., 1983, 24, 44054408.

29 C. Ikeda, R. Braun and B. Sorenson, J. Org. Chem., 1964, 29, 286-290.

30 P. G. M. Wuts and T. W. Greene, in Greene's Protective Groups in Organic Synthesis, John Wiley \& Sons, Inc., 2006, pp. 431532. 
31 It was found that $0.5 \mathrm{M}$ and a 5 hour reaction time were optimal for the range of substrates explored.

32 It is worth noting that the two isomers were separable by column chromatography, allowing the $Z, Z$-product to be isolated cleanly.

33 R. Hemelaere, F. Carreaux and B. Carboni, J. Org. Chem., 2013, 78, 6786-6792.

34 (a) G. A. Molander and L. A. Felix, J. Org. Chem., 2005, 70, 3950-3956; (b) E. M. Woerly, J. R. Struble, N. Palyam, S. P. O'Hara and M. D. Burke, Tetrahedron, 2011, 67, 43334343; (c) N. Miyaura and A. Suzuki, Chem. Rev., 1995, 95, 2457-2483.

35 The reaction was conducted at $20{ }^{\circ} \mathrm{C}$ in order to minimize loss of the volatile substrate. A less volatile vinyl epoxide has been shown to generate higher yield (ref. 19).
36 At 5 hours some $Z$ to $E$ isomerization of the product had occurred. Investigations into the cause of this isomerization are currently in progress.

37 S. D. Goldberg and R. H. Grubbs, Angew. Chem., 2002, 114, 835-838.

38 (a) T. R. Kelly, Y. Lee and R. J. Mears, J. Org. Chem., 1997, 62, 2774-2781; (b) D. A. Dias and M. A. Kerr, Org. Lett., 2009, 11, 3694-3697; (c) S. Cacchi, G. Fabrizi, L. Moro and P. Pace, Synlett, 1997, 1367-1370.

39 T. Sakai, K. Kazuhiko, S. Tsuboi, M. Utaka and A. Takeda, Bull. Chem. Soc. Jpn., 1987, 60, 2911-2915.

40 B. H. Lipshutz, Synth. Commun., 1982, 12, 267-277.

41 Prolonged reaction times led to noticeable isomerization.

42 (a) R. E. Ireland and M. D. Varney, J. Org. Chem., 1986, 51, 635-648; (b) M. Bonin, J. Royer, D. S. Grierson and H. P. Husson, Tetrahedron Lett., 1986, 27, 1569-1572. 